\title{
SAFETY TEST ON IRRADIATED AGR-1 COMPACT 4-2-2
}

\author{
J.D. Hunn, R.N. Morris, C.A. Baldwin, and F.C. Montgomery
}

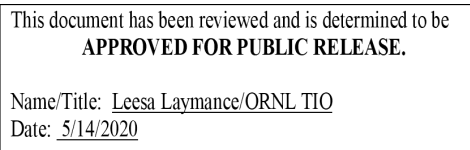

Post-irradiation examination (PIE) is in progress on coated particle fuel compacts from the first Advanced Gas Reactor (AGR) Fuel Development and Qualification irradiation experiment (AGR-1). The $A G R-1$ Post-Irradiation Examination Plan (INL/PLN-2828, Rev. 1) includes safety testing of the irradiated compacts in the Oak Ridge National Laboratory (ORNL) Core Conduction Cooldown Test Facility (CCCTF) and the Idaho National Laboratory (INL) Fuel Accident Condition Simulator (FACS) to evaluate the effect of elevated temperature on the fuel microstructure and fission product retention. Standard safety tests involve heating compacts to maximum temperatures of 1600,1700 , or $1800^{\circ} \mathrm{C}$ for typically 300 hours, where $1600^{\circ} \mathrm{C}$ is the expected maximum temperature during a high-temperature gascooled reactor (HTGR) depressurization conduction cooldown event, while 1700 and $1800^{\circ} \mathrm{C}$ explore the performance margin. The Compact 4-2-2 safety test was conducted using multiple hold temperatures from $1000-1600^{\circ} \mathrm{C}$ to investigate fission product retention at temperatures below $1600^{\circ} \mathrm{C}$ and during thermal cycling, with particular emphasis on silver retention behavior [INL/PLN-4714]. Previous tests produced unusual silver releases when temperatures were inadvertently or intentionally cycled between room temperature and $1600^{\circ} \mathrm{C}$ [ORNL/LTR-2012/396]; the Compact 4-2-2 test was designed to reproduce and explore these observations.

AGR-1 Compact 4-2-2 was irradiated at the INL Advanced Test Reactor (ATR) to an average calculated burnup of $16.6 \%$ fissions per initial metal atom (FIMA) and an average calculated fast fluence of $3.73 \cdot 10^{25} \mathrm{n} / \mathrm{m}^{2}$, at a calculated time-averaged and volume-averaged temperature of approximately $1065^{\circ} \mathrm{C}$. After capsule disassembly in the INL Hot Fuel Examination Facility (HFEF), metrology [INL/EXT-10-20722] and gamma scanning [INL/ECAR-1682, Rev. 2] were performed. The compact was then shipped to ORNL for safety testing and additional PIE. The Compact 4-2-2 safety test began on May 5, 2014 and ended on June 4, 2014.

During the safety test, as the compact was heated, condensable fission products (metallic elements) were collected by the CCCTF in-furnace cold finger and gaseous fission products were collected from the helium sweep gas as it passed through liquid nitrogen-cooled cold traps. Deposition cups attached to the in-furnace cold finger were periodically removed and analyzed by gamma spectrometry and the sweep gas traps were constantly monitored for gamma activity throughout each run. As originally designed, the cooled-deposition cups have a high efficiency for collection of silver and cesium at $1600-1800^{\circ} \mathrm{C}$, and the sweep gas trap system has a good sensitivity to release of ${ }^{85} \mathrm{Kr}$. Time-dependent monitoring of europium and strontium (not originally part of the CCCTF design) includes a larger uncertainty, due to the fact that these elements can be retained by the graphite and tantalum furnace internals; analysis of the CCCTF furnace internals at the end of each test is important for accurate assessment of the total cumulative release of these elements. For a typical $1600^{\circ} \mathrm{C}$ safety test, the fraction of europium that eventually accumulates on the deposition cups has been 10-13\%, while silver collection efficiency is typically above $95 \%$.

After completion of each safety test, additional analysis is performed on the deposition cups and other CCCTF furnace internals (graphite fuel holder, tantalum furnace liner, and tantalum gas inlet line) to measure the activity from the radioactive fission products that have been transferred from the compact to these various furnace components. For a standard (single-temperature) safety test, an average deposition cup collection efficiency is determined for each fission product by measuring the total release from the compact (summing the inventories measured on the deposition cups, graphite holder, and tantalum furnace internals), and calculating the fraction of the total that went to the cups. The average collection efficiency is then used to adjust the time-dependent deposition cup data to estimate the time-dependent fission product release from the compact. However, for the Compact 4-2-2 safety test, this approach is not 
viable because the deposition cup collection efficiency is expected to vary as a function of temperature, so an average taken over a time period involving holds at different temperatures would not be representative of the average collection efficiency during each hold. Therefore, time-dependent data for this test are simply presented in terms of the fission product fractions collected on the deposition cups.

\section{Safety Test Results}

The overall temperature profile and time-dependent silver results are shown in Figure 1. The plotted results show the cumulative fraction of the Compact 4-2-2 calculated fission product inventory [INL/ECAR-958, Rev. 2] that was collected on the deposition cups. (Compact gamma scanning prior to safety testing [INL/ECAR-1682, Rev. 2] determined that $60 \%$ of the Compact $4-2-2$ calculated ${ }^{110 \mathrm{~m}} \mathrm{Ag}$ inventory was previously released during the AGR-1 irradiation test in the ATR.)

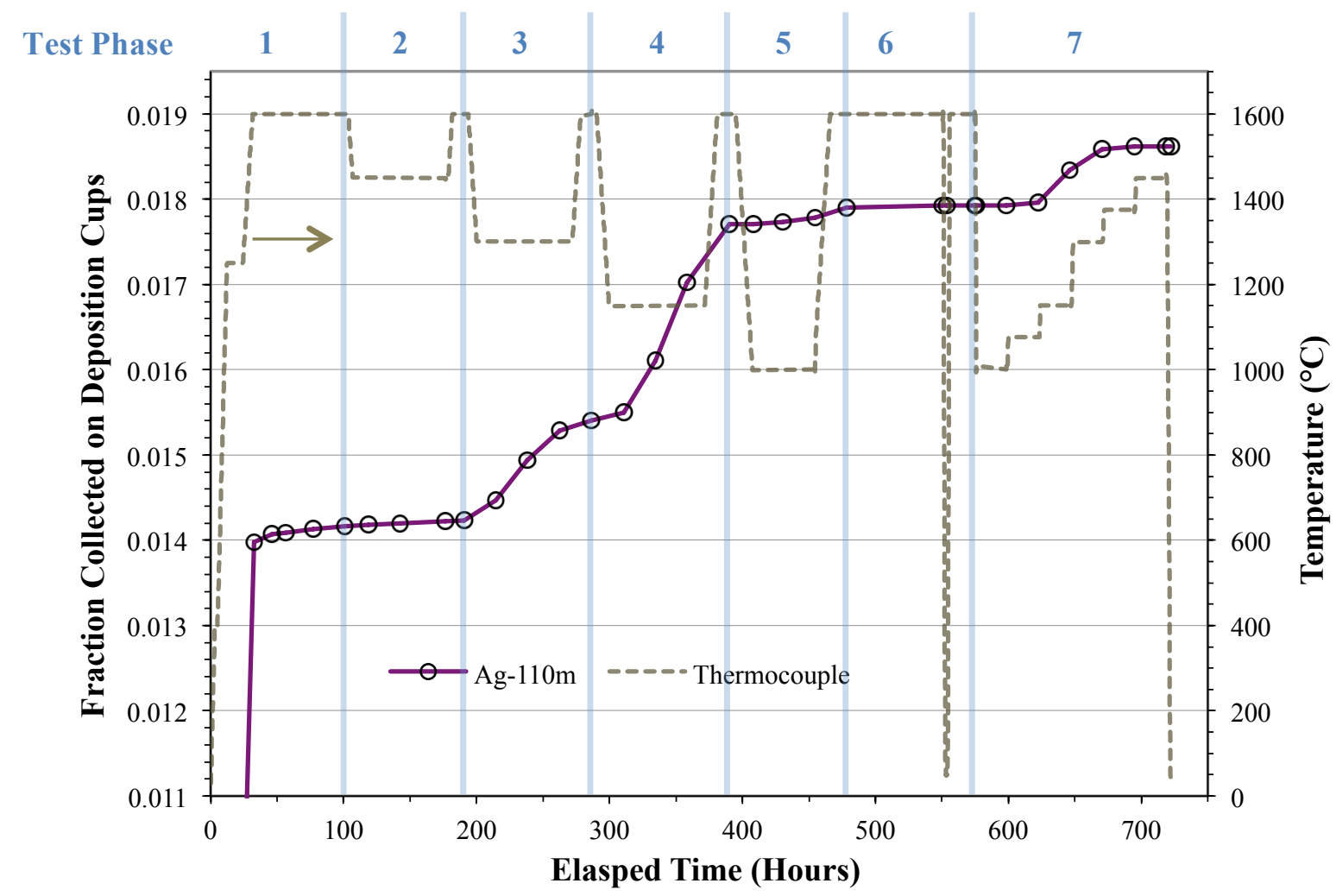

Figure 1. Collection of ${ }^{110 \mathrm{~m}} \mathrm{Ag}$ from Compact 4-2-2 during multiple-temperature safety testing. Data points show the end of each cup collection period.

The compact was initially taken to a maximum test temperature of $1600^{\circ} \mathrm{C}$ and held there for $72 \mathrm{~h}$. Based on results from previous $1600^{\circ} \mathrm{C}$ tests, this amount of time at $1600^{\circ} \mathrm{C}$ was expected to flush most of the silver out of the compact matrix and outer pyrolytic carbon layer $(\mathrm{OPyC})$ and deposit it on the deposition cups. Figure 1 shows that $98.7 \%$ of the initial silver release in Phase 1 was detected within the first hour after reaching $1600^{\circ} \mathrm{C}$. Subsequent cups exchanged during this first $1600^{\circ} \mathrm{C}$ hold showed very little additional silver accumulation (only $1.3 \%$ of the total at that point). This agreed with the expectation that silver remaining in the matrix and $\mathrm{OPyC}$ due to release through intact $\mathrm{SiC}$ would be released by the initial 72 hour soak at $1600^{\circ} \mathrm{C}$. When the temperature was reduced to $1450^{\circ} \mathrm{C}$ in Phase 2, additional silver collection was negligible. Because the deposition cup collection efficiency at $1450^{\circ} \mathrm{C}$ was not specifically known and estimated to be $\sim 70 \%$ based on CCCTF historical data, at the end of Phase 2, the furnace was heated back up to $1600^{\circ} \mathrm{C}$, where collection efficiency is expected to be $>95 \%$, to try to ensure any exposed silver was collected on the last cup in that phase. However, silver accumulation remained negligible. 
In Phase 3, the temperature was dropped to $1300^{\circ} \mathrm{C}$ and significant silver was collected on each cup during the run. This was a surprising result, given that silver release had already flattened out at higher temperatures. In Phase 4, the process was repeated with an $1150^{\circ} \mathrm{C}$ hold. Again significant additional silver accumulated on the deposition cups (about twice what was detected during the $1300^{\circ} \mathrm{C}$ hold). The increased accumulation of silver during Phases 3 and 4, after the apparent depletion of silver from the matrix and OPyC during Phases 1 and 2, suggests that additional silver was released through intact SiC coatings. At the end of Phases 3 and 4, the furnace was heated back up to $1600^{\circ} \mathrm{C}$, but there was no large increase in the silver collection that might indicate that the silver presumably released through the $\mathrm{SiC}$ was significantly held up in the $\mathrm{OPyC}$ and matrix, or trapped elsewhere in the furnace at low temperature and released to the cup as the teperature was raised.

Figure 2 shows the average ${ }^{110 \mathrm{~m}} \mathrm{Ag}$ collection rate (fraction collected on each cup divided by the residence time). This shows how the silver collection rate rapidly dropped off after the first hour at $1600^{\circ} \mathrm{C}$ and stayed low through the remainder of Phases 1 and 2. At the beginning of Phase 3, the silver collection rate increased dramatically. The first Phase 3 cup only collected about half the silver as the second, but this was biased by the fact that the furnace was cooled slowly and was only at 1300 for the latter $58 \%$ of the first collection period. (Collection periods during Phases 1-5 were 24 hours each.) The fourth Phase 3 cup had a lower average collection rate than the others because the furnace was only at $1300^{\circ} \mathrm{C}$ for the first $42 \%$ of the fourth collection period. Very little silver was collected on the first Phase 4 cup, partially due to the slow cooldown limiting the dwell time at lower temperature, but also probably due to a slower migration of silver to the deposition cup at $1150^{\circ} \mathrm{C}$ resulting in a delay period before silver released from the particles started collecting on the cups. The average collection rate increased during the second and third collection periods at $1150^{\circ} \mathrm{C}$, eventually reaching a rate almost double that observed at $1300^{\circ} \mathrm{C}$. The fourth Phase 4 cup had a $56 \%$ lower average collection rate than the previous cup, but it was only at $1150^{\circ} \mathrm{C}$ for about $41 \%$ of the collection period, so this seems to indicate the silver release rate remained near its peak until the furnace was heated above $1150^{\circ} \mathrm{C}$ and the rate dropped to that observed at higher tempertures.

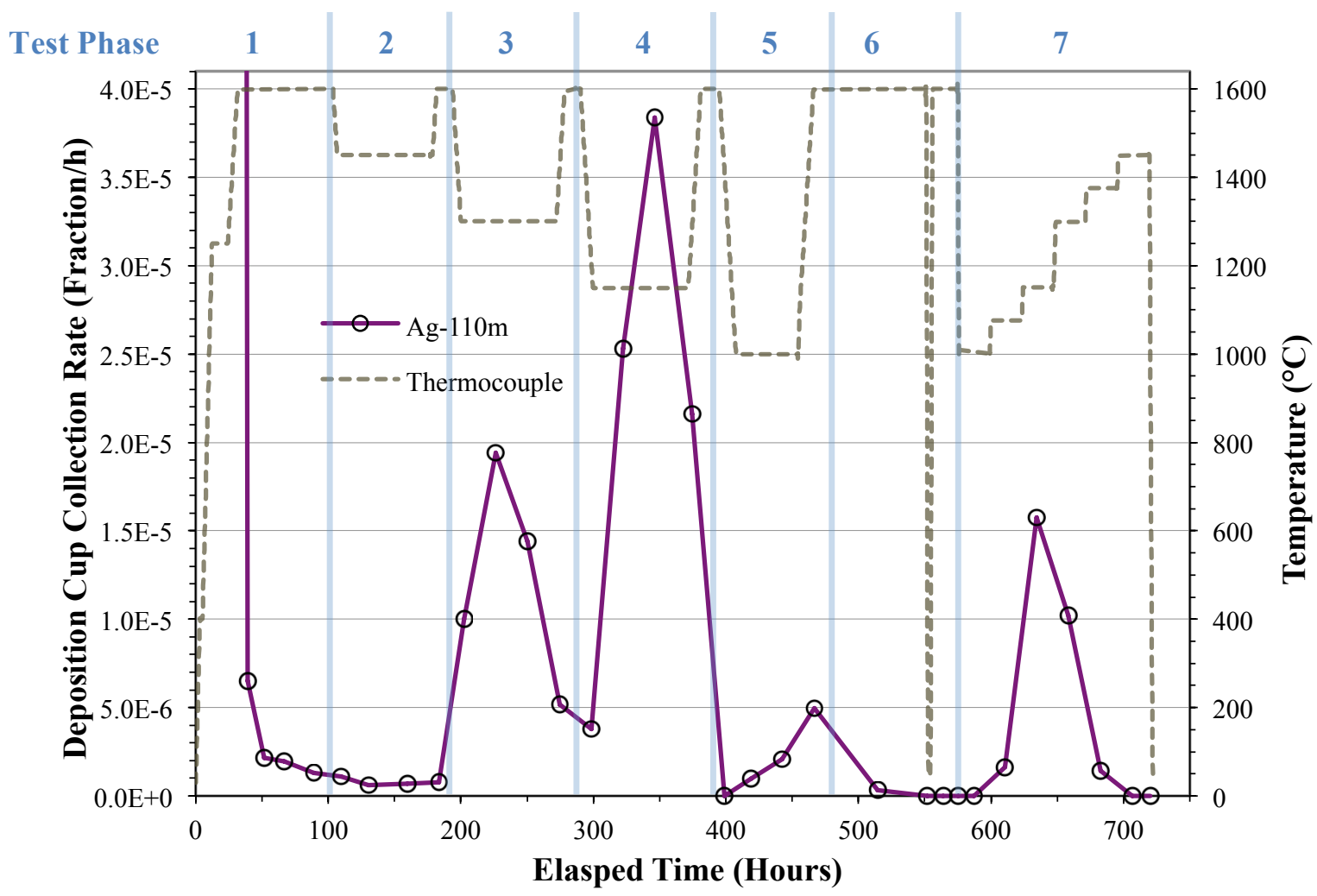

Figure 2. Collection of ${ }^{110 \mathrm{~m}} \mathrm{Ag}$ from Compact 4-2-2 during multiple-temperature safety testing. Data points show the middle of each cup collection period. 
During the Phase 5 hold at $1000^{\circ} \mathrm{C}$, silver collection rate dropped below that observed at 1300 and $1150^{\circ} \mathrm{C}$, but not as low as observed at 1450 and $1600^{\circ} \mathrm{C}$. The rate continued to increase throughout Phase 5, again indicating a delay in the transport of silver to the deposition cups at the lower test temperatures; this is not surprising since the vapor pressure drops exponentially as the melting point $\left(962^{\circ} \mathrm{C}\right)$ is approached. The average collection rate at the end of Phase 5 was probably positively biased by the time spent in the temperature range between 1150 and $1300^{\circ} \mathrm{C}$ during the ramp back to $1600^{\circ} \mathrm{C}$.

Phase 6 involved another 72 -hour hold at $1600^{\circ} \mathrm{C}$, during which silver release continued to be negligible, followed by a quick thermal cycle to room temperature and back. No measurable silver release was detected after this thermal cycle. (The ramp rate for this thermal cycle was increased in order to reduce the dwell time at temperatures around 1150 and $1300^{\circ} \mathrm{C}$.) In Phase 7 , temperature was dropped to $1000^{\circ} \mathrm{C}$ using the same rapid ramp rate, and then stepped back up to $1450^{\circ} \mathrm{C}$ in 24 -hour intervals. Neglible silver was deposited on the cups at 1000 and $1075^{\circ} \mathrm{C}$, silver collection rate peaked at $1150^{\circ} \mathrm{C}$ and remained high at $1300^{\circ} \mathrm{C}$, deposition dropped off again at 1375 , and was negligible at $1450^{\circ} \mathrm{C}$. The Phase 7 releases agreed with the earlier results and further refined the temperature range at which silver release appeared to be active.

Figure 3 shows the cumulative fractional deposition of the other measurable radioisotopes over the first six phases. Cesium release was very low; only ${ }^{134} \mathrm{Cs}$ is reported because ${ }^{137} \mathrm{Cs}$ activities were below the detection limit for this longer-lived isotope, which has higher background interference from several decades of accumulated hot cell contamination. The low cesium collection, even at $1600^{\circ} \mathrm{C}$, indicates that no particles experienced $\mathrm{SiC}$ failure. Europium and strontium results are interesting because they show trends that are nearly opposite to the silver data trends in Figure 1. Europium and strontium collection rates were the highest at $1600^{\circ} \mathrm{C}$, moderate at $1450^{\circ} \mathrm{C}$, and essentially negligible at the lower temperatures. This does not necessarily indicate europium and strontium were being released through intact $\mathrm{SiC}$ at $1600^{\circ} \mathrm{C}$, but more likely indicates a temperature-dependent reduction in the transport rate of europium and strontium from the matrix and $\mathrm{OPyC}$, through the graphite holder, and to the deposition cups. Results during Phase 7 were similar, with no measurable collection of europium and strontium until $1450^{\circ}$ was reached.

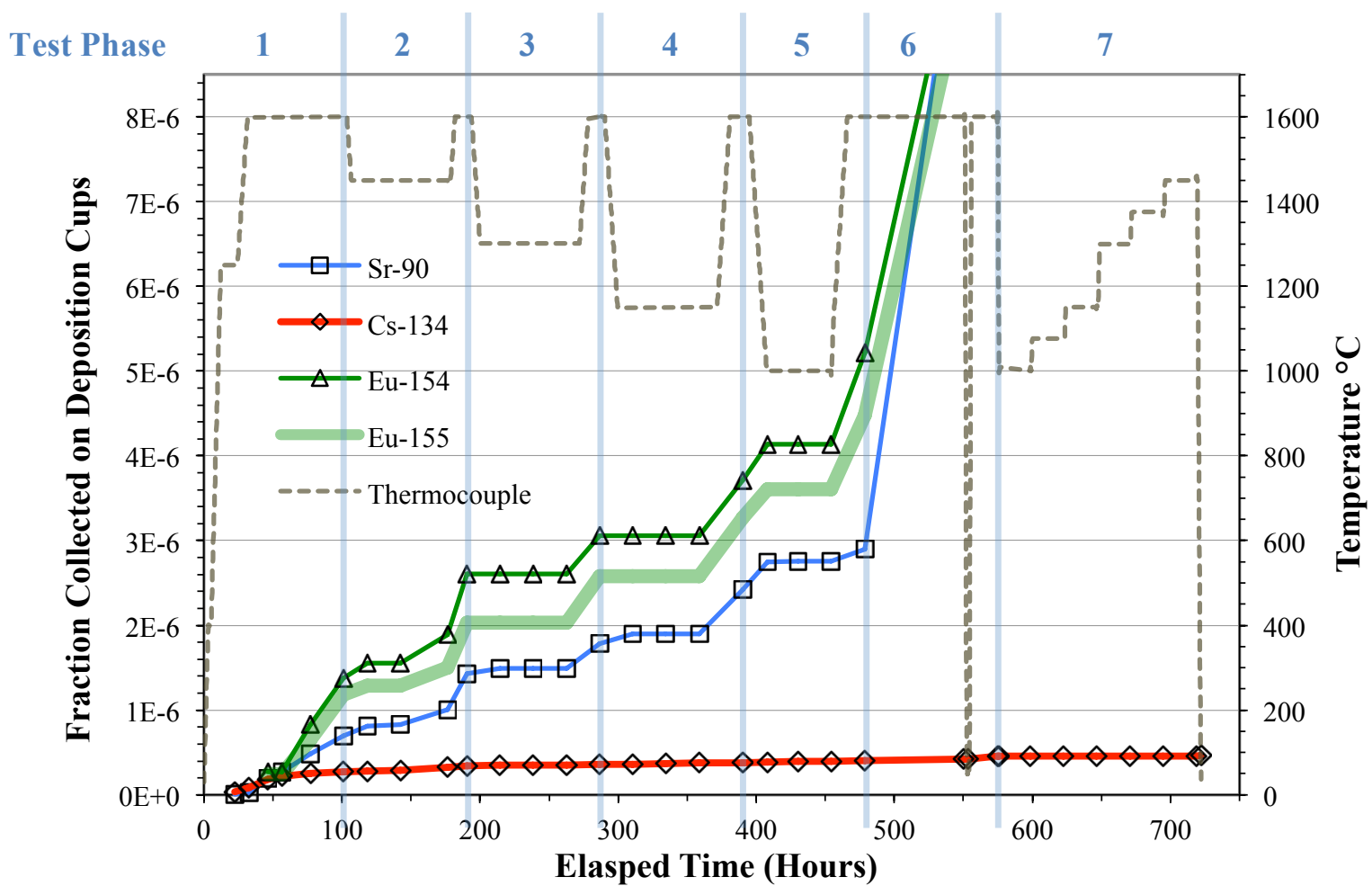

Figure 3. Collection of other radioisotopes from Compact 4-2-2. Data points show the end of each cup collection period. 
Table 1 lists the fraction of the total furnace test releases detected on various internal CCCTF furnace components at the end of the safety test. The europium and strontium distributions exhibit the expected slow release of these elements from the graphite holder (europium and strontium inventory remaining in the compact matrix and $\mathrm{OPyC}$ were even higher than what was held in the graphite holder). Because the cesium release was very low, cesium distributions may be more indicative of contributions from hot cell contamination than reflective of cesium transport between these components. Silver distribution, however, was anomalous to typical CCCTF behavior, perhaps because of the lower test temperatures. (The furnace is usually operated from $1400-1800^{\circ} \mathrm{C}$ and the deposition cup is located for best collection at these temperatures.) An unusually large fraction (69.1\%) of the total detected ${ }^{110 \mathrm{~m}} \mathrm{Ag}$ was located at the top of the furnace on the tantalum gas inlet line (above the deposition cup). The mechanism by which the silver bypassed the deposition cups to be deposited on the gas line is currently a mystery, and whether this may possibly impact the interpretation of the observed collection of ${ }^{110 \mathrm{~m}} \mathrm{Ag}$ on the deposition cups is not known. A significant concern is the possibility that silver collected on the cups at 1150 and $1300^{\circ} \mathrm{C}$ may have come from the top of the furnace rather than from the compact; however, this seems unlikely because it would involve silver moving from a cooler zone to a warmer one. The fact that silver was not collected on the cups as the temperature was raised from the lower temperatures to $1600^{\circ} \mathrm{C}$, suggests that silver migration from furnace components to the deposition cups was not an issue.

Table 1. Distribution of radioactive isotopes detected in the CCCTF furnace internals after the Compact 4-2-2 furnace test

\begin{tabular}{|c||c|c|c|c|c|}
\hline Component & ${ }^{\mathbf{9 0}} \mathbf{S r}$ & ${ }^{\mathbf{1 3 4}} \mathbf{C s}$ & ${ }^{{ }^{110 m}} \mathbf{A g}$ & ${ }^{\mathbf{1 5 4}} \mathbf{E u}$ & ${ }^{\mathbf{1 5 5}} \mathbf{E u}$ \\
\hline \hline Deposition cups & $4.6 \%$ & $52.8 \%$ & $30.9 \%$ & $2.7 \%$ & $2.1 \%$ \\
\hline Tantalum parts & $15.2 \%$ & $22.6 \%$ & $69.1 \%$ & $12.7 \%$ & $13.1 \%$ \\
\hline Graphite holder & $80.1 \%$ & $24.6 \%$ & $0 \%$ & $84.6 \%$ & $84.8 \%$ \\
\hline
\end{tabular}

\section{Conclusion}

A multiple-temperature furnace test of Compact 4-2-2 was conducted to investigate previous unexpected silver releases that occurred in a few early AGR-1 safety tests due to power failures and other CCCTF issues. The previously observed silver releases appear to have been successfully duplicated by holding the furnace temperature at 1150 or $1300^{\circ} \mathrm{C}$. Results of this multiple-temperature test showed that once silver (previously released during irradiation) had been flushed out of the compact matrix and OPyC, additional silver could be collected by dropping the furnace temperature into a lower temperature range. This suggests a release mechanism for silver through intact $\mathrm{SiC}$ that is only active in a limited temperature range that is below the standard $1600-1800^{\circ} \mathrm{C}$ safety test temperatures and at the high end of gas reactor operating temperatures.

Additional experiments need to be performed to further verify the validity of these test results, address several weaknesses in the current experiment, and provide additional data regarding the apparent release mechanism. AGR-2 fuel will soon be available for testing to address the primary issue of the low ${ }^{110 \mathrm{~m}} \mathrm{Ag}$ activity in Compact 4-2-2 at the time of the multiple-temperature furnace test. At the time of the test, Compact 4-4-2 (already at 40\% of its calculated inventory due to high in-core silver release) had gone through $6.8^{110 \mathrm{~m}} \mathrm{Ag}$ half lives. The possible existence and contribution from thermal gradients within the compact when heated at lower temperature should be considered, as this could possibly impact release behavior. In order to be able to better quantify the compact release rates, collection efficiencies at the lower test temperatures need to be determined, and possibly increased. Future tests should also concentrate on temperatures in the $1150-1300^{\circ} \mathrm{C}$ regime and hold these temperatures for longer testing periods; perhaps limiting each test to a single safety test temperature to allow for post-safety test determination of the average deposition cup collection efficiency for use in estimating time-dependent compact releases. 


\section{Acknowledgments}

This work was supported by the U.S. Department of Energy, Office of Nuclear Energy, under the Very High Temperature Reactor Technology Development Office Advanced Gas Reactor Fuel Development and Qualification Program. Hot cell activities were supported by the staff of the ORNL Irradiated Fuels Examination Laboratory (IFEL), and analysis of deposition cups and internal furnace component leach solutions was provided by the ORNL Nuclear Analytical Chemistry \& Isotopics Lab. 